\title{
Accumulation of epicardial fat rather than visceral fat is an independent risk factor for left ventricular diastolic dysfunction in patients undergoing peritoneal dialysis
}

Heng-Hsu Lin ${ }^{1 \dagger}$, Jen-Kuang Lee $2,3,4 \dagger$, Chung-Yi Yang ${ }^{5}$, Yu-Chung Lien ${ }^{6}$, Jenq-Wen Huang ${ }^{6}$ and Cho-Kai Wu ${ }^{7,8^{*}}$

\begin{abstract}
Background: Symptoms of heart failure with preserved left ventricular systolic function are common among patients undergoing peritoneal dialysis (PD). Epicardial fat (EpF) is an ectopic fat depot with possible paracrine or mechanical effects on myocardial function. The aim of our current study is to assess the association between EpF and Left ventricular diastolic dysfunction (LVDD) in patients undergoing PD and to clarify the relationships among EpF, inflammation, and LVDD in this population.
\end{abstract}

Methods: This was a cross-sectional study of 149 patients with preserved left ventricular systolic function who were undergoing PD. LVDD was diagnosed (according to the European Society of Cardiology guidelines) and EpF thickness measured by echocardiography. The patients without LVDD were used as controls. The serum inflammatory biomarker high-sensitivity C-reactive protein (hsCRP) was measured. The location and amount of adipose tissue were assessed by computed tomography (CT) at the level of the fourth lumbar vertebra.

Results: Subjects with LVDD had higher levels of hsCRP, more visceral and peritoneal fat, and thicker EpF (all $p<0.001$ ) than controls. Visceral adipose tissue, hsCRP, and EpF all correlated significantly $(p<0.05)$ with LVDD. Multivariate regression analysis rendered the relationship between visceral adipose tissue and LVDD insignificant, whereas EpF was the most powerful determinant of LVDD (odds ratio $=2.41,95 \%$ confidence interval $=1.43-4.08$, $p<0.01)$. EpF thickness also correlated significantly with the ratio of transmitral Doppler early filling velocity to tissue Doppler early diastolic mitral annular velocity (E/e'; $r=0.27, p<0.01$ ).

Conclusion: EpF thickness is significantly independently associated with LVDD in patients undergoing PD and may be involved in its pathogenesis.

Keywords: Diastolic dysfunction, Epicardial fat, Inflammation, Echocardiography

\section{Introduction}

Cardiovascular disease (CVD) is the most common cause of mortality and morbidity among patients with end-stage renal disease (ESRD) undergoing either hemodialysis or peritoneal dialysis (PD) [1]. Patients with ESRD are prone

\footnotetext{
* Correspondence: chokaiwu@yahoo.com.tw

${ }^{\dagger}$ Equal contributors

${ }^{7}$ Division of Cardiology, Department of Internal Medicine, National Taiwan University College of Medicine and Hospital No. 7, Chung-Shan South Road Taipei 100, Taipei, Taiwan

${ }^{8}$ Graduate Institute of Clinical Medicine, College of Medicine, National Taiwan University, Taipei, Taiwan

Full list of author information is available at the end of the article
}

to hypertension and left ventricular hypertrophy (LVH), which is a physiological response to pressure and volume overload. They also suffer disproportionately from fluid overload and systemic inflammation [2,3]. We recently found an interaction between PD and inflammation that further aggravates left ventricular diastolic dysfunction (LVDD) [4]. All of these contribute to the high prevalence of LVDD in patients undergoing PD [2,5]. Although LVDD could be an independent prognostic marker in patients with complex comorbidities [6], there, as yet, is scant information on the mechanisms of the pathogenesis of LVDD in patients undergoing PD. 
Patients undergoing PD encounter complex nutritional problems. One of the most undesirable effects associated with PD is an increase in body fat mass $[7,8]$. Changes in body composition, including fat distribution, in patients undergoing PD are well described $[9,10]$. The distribution of body fat plays a pivotal role in the development and progression of both diastolic and systolic heart failure [11]. Epicardial fat (EpF) is the true visceral fat depot of the heart and accounts for approximately $20 \%$ of total heart weight [12]. There are currently several methods for evaluating EpF, including echocardiography, computed tomography (CT), and magnetic resonance image (MRI). Echocardiographic EpF measurement is the easiest method, and such measurements have been proven independently predictive of visceral adiposity and well correlated with myocardial fat $[12,13]$. EpF is a source of several proinflammatory and proatherogenic cytokines that influence cardiac function [13,14]. EpF also correlates with several cardiac comorbidities, including coronary artery disease (CAD) and left ventricular dysfunction [15-17]. However, there is as yet no evidence that the EpF thickness in patients receiving PD relates to LVDD.

Therefore, the present study was performed to assess the association between EpF and LVDD in patients undergoing $\mathrm{PD}$ and to clarify the relationships among EpF, inflammation, and LVDD in this population.

\section{Material and methods}

\section{Study participants and study design}

Between July 2007 and March 2009, 149 homogenous Taiwanese patients who had undergone PD using a conventional glucose-based lactate-buffered PD solution (UltraBag; Baxter Healthcare SA, Singapore) for $>6$ months at the specialty peritoneal dialysis clinic at the National Taiwan University Hospital were consecutively enrolled. Patients with hepatic disease, a history of myocardial infarction, coronary intervention, cardiac myopathy, or pericardial disease, chronic obstructive pulmonary disease, chronic atrial fibrillation, clinical signs of acute infection, or other chronic inflammatory conditions were excluded, as were patients taking statins, lipid-lowering agents, and/ or other medication that could potentially influence relevant plasma parameters. All subjects underwent echocardiography and abdominal CT examination. In total, 65 participants were diagnosed with LVDD as defined by our previous reports and the recent consensus statement of the European Society of Cardiology. In brief, LVDD was defined echocardiographically by a ratio of early mitral valve flow velocity $(E)$ to early diastolic lengthening velocity (e'; E/e') during tissue Doppler imaging of $\geq 15$ or by a combination of $15>E / e^{\prime} \geq 8$, a mitral inflow E/A ratio $<0.5$, and a deceleration time $>280$ [18-20]. The remaining 84 subjects without LVDD served as the control group.
Written informed consent was obtained from every participating subject, and the study was approved by the institutional review board of the National Taiwan University Hospital.

\section{Biochemical data}

Blood samples were collected from all patients from the antecubital vein between 8:00 AM and 10:00 AM with the patient in a supine position after fasting for $12 \mathrm{hr}$. No patient underwent PD exchange before sampling. Plasma glucose and serum total cholesterol (TC), high-density lipoprotein cholesterol (HDL), low-density lipoprotein cholesterol (LDL), triglycerides (TG), and high-sensitivity C-reactive protein (hsCRP) levels were determined using an automatic analyzer (Toshiba TBA 120FR, Toshiba Medical Systems Co., Ltd., Tokyo, Japan). All samples were processed blindly by examiners who were unaware of the patients' clinical characteristics.

\section{Echocardiography and measurement of EpF}

Left atrial (LA) diameter, the LV end-diastolic and systolic diameters, interventricular septum thickness, LV posterior wall thickness, mitral inflow early rapid filling wave (E), peak velocity of the late filling wave due to atrial contraction (A), E/A ratio, E wave deceleration time, and mitral annular early diastolic velocity were measured according to the American Society of Echocardiography guidelines using an iE33 xMATRIX echocardiography system (Philips Healthcare, Best, the Netherlands). The LV mass index was calculated from the LV end-diastolic and systolic diameters, interventricular septum thickness, and LV posterior wall thickness according to the method of Devereux et al. [21]. The peak annular early and late diastolic velocities of the lateral mitral annulus during tissue Doppler imaging (e' and a') were also recorded. Doppler and color Doppler studies were performed to detect valvular heart disease. Significant valvular heart disease was defined as at least moderate aortic or mitral stenosis/regurgitation. EpF was measured by 2 readers with no knowledge of the patients' baseline characteristics according to previously published methods [22]. In brief, EpF was identified as the echocardiographically free space between the outer wall of the myocardium and the visceral layer of the pericardium, and its thickness was measured perpendicularly to the free wall of the right ventricle at end-systole over 3 cardiac cycles (Figure 1). The mean value of 3 cardiac cycles from each echocardiographic view (including both parasternal long- and short-axis views) was recorded as the EpF thickness. Repeat analysis of 20 patients was performed by either the same or a second observer. Inter-observer correlation coefficients were 0.89 whereas intra-observer correlation coefficients were 0.93 . 


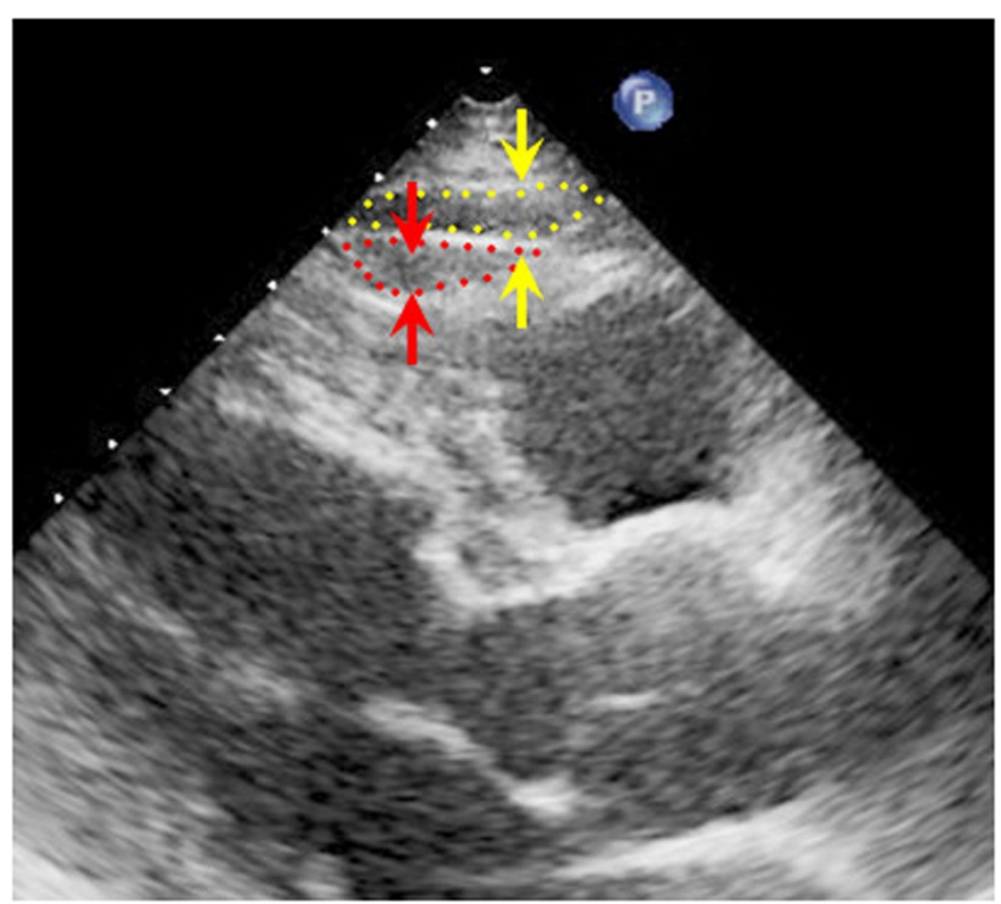

Figure 1 Echocardiographic images of a 55-year-old male patient with hypertension, dyslipidemia, and diabetes. The red area is the epicardial fat within the pericardial sac as quantified 3-dimensionally by echocardiography.

\section{Determination of adipose tissue distribution by CT}

Each subject was imaged using a 16-MDCT scanner (LightSpeed 16, GE Healthcare, Milwaukee, WI, USA). The images were analyzed using image analysis software (ImageJ, version 1.43q; National Institutes of Health, Bethesda, MD, USA) with an attenuation range of -50 to -250 Hounsfield units to quantify the subcutaneous, visceral, and total abdominal adipose tissue areas at the level of the umbilicus. The results were expressed in centimeter square. The visceral/subcutaneous adipose tissue area ratio (V/S ratio) was calculated.

\section{Statistical analysis}

Analyses were performed using SPSS 16.0 for Windows XP (SPSS, Inc., Chicago, IL, USA). The KolmogorovSmirnov test was used to determine whether the data were normally distributed. Data for continuous variables that were not normally distributed were transformed using the Napierian logarithm. Baseline characteristics and echocardiographic findings were compared between groups using Student's unpaired $t$ test for continuous data and a chisquared test for categorical data. Comparisons of mean values across groups and correlations between continuous variables were assessed via linear regression. Odds ratios (ORs) and 95\% confidence intervals (CIs) were estimated by logistic regression. Associations between EpF and echocardiographic diastolic function parameters were determined using Pearson's correlation coefficient. Multivariate models were used to assess the associations of adipose tissue and serum biomarkers with LVDD. Covariates associated with LVDD, including age, diabetes, hypertension, and the natural logarithms of the LDL level and left ventricular mass index, were incorporated. All $\mathrm{p}$ values were 2 -sided, and $\mathrm{p}$ values $<0.05$ were considered indicative of statistical significance.

\section{Results}

\section{Demographics}

Of the 149 subjects in our sample population, 65 were diagnosed with LVDD, and the remainder served as controls. The baseline characteristics of the participants in both groups are summarized in Table 1. Consistent with previous reports on hypertension, the subjects with LVDD were predominantly female, older, and suffered more frequently from hypertension or hyperlipidemia (higher LDL level). Patients with LVDD had significantly higher hsCRP levels (Table 1). The cause of renal failure and the residual renal function did not differ between the groups. Relative to the control group, subjects with LVDD had larger enddiastolic and systolic LV volumes $(p<0.05)$, greater LA diameters, and larger indexed LV mass values $(\mathrm{p}<0.05)$. Comparison of the functional parameters showed a prolonged deceleration time (DT) $(\mathrm{p}<0.05)$, increased mitral inflow late filling wave $(\mathrm{p}<0.001)$, decreased mitral inflow E/A ratio ( $\mathrm{p}<0.005)$, and decreased peak annular early diastolic velocity of the lateral mitral annulus in 
Table 1 Baseline demographic data, echocardiographic characteristics, and adipose tissue measurements of the 149 patients undergoing peritoneal dialysis included in the study

\begin{tabular}{|c|c|c|c|}
\hline Baseline characteristics & $\begin{array}{l}\text { No LVDD } \\
(n=84)\end{array}$ & $\begin{array}{l}\text { LVDD } \\
(n=65)\end{array}$ & $\mathrm{p}$ \\
\hline Age (years) & $53.4 \pm 14.8$ & $57.8 \pm 11.7$ & $0.035^{*}$ \\
\hline Women (\%) & $43(51)$ & $40(62)$ & 0.25 \\
\hline HTN (n) & 50 & 56 & $<0.001^{*}$ \\
\hline $\mathrm{DM}(\mathrm{n})$ & 23 & 25 & 0.16 \\
\hline Fasting plasma glucose (mg/dL) & $96.2 \pm 19.5$ & $97.3 \pm 11.8$ & 0.69 \\
\hline $\mathrm{HDL}(\mathrm{mg} / \mathrm{dL})$ & $38.9 \pm 8.3$ & $41.7 \pm 12.6$ & 0.26 \\
\hline $\mathrm{LDL}(\mathrm{mg} / \mathrm{dL})$ & $83.2 \pm 33.5$ & $99.1 \pm 38.0$ & $0.05^{*}$ \\
\hline $\mathrm{TG}(\mathrm{mg} / \mathrm{dL})$ & $125.3 \pm 85.3$ & $142.4 \pm 96.1$ & 0.23 \\
\hline Height $(\mathrm{cm})$ & $163 \pm 5.9$ & $162 \pm 6.5$ & 0.30 \\
\hline Body weight (kg) & $59 \pm 10.5$ & $60 \pm 11.7$ & 0.82 \\
\hline BMI $\left(\mathrm{kg} / \mathrm{m}^{2}\right)$ & $23 \pm 3.9$ & $24 \pm 3.2$ & 0.46 \\
\hline $\mathrm{CRP}(\mathrm{mg} / \mathrm{dL})$ & $0.74 \pm 0.99$ & $2.13 \pm 1.73$ & $<0.001^{*}$ \\
\hline \multicolumn{4}{|l|}{ Primary renal diagnosis } \\
\hline $\mathrm{DM}$ & 29 & 25 & 0.61 \\
\hline CGN & 25 & 17 & 0.59 \\
\hline Other & 30 & 23 & 0.87 \\
\hline Time on PD (h) & $18.9 \pm 1.6$ & $19.1 \pm 1.3$ & 0.46 \\
\hline $\mathrm{Kt} / \mathrm{N}$ & $1.72 \pm 0.34$ & $1.91 \pm 0.25$ & 0.57 \\
\hline Residual renal function $(\mathrm{mL} / \mathrm{min})$ & $1.94 \pm 0.31$ & $2.31 \pm 0.22$ & 0.25 \\
\hline \multicolumn{4}{|l|}{ Echocardiographic characteristics } \\
\hline LV end-diastolic diameter ( $\mathrm{mm}$ ) & $48.4 \pm 6.7$ & $50.9 \pm 7.4$ & $0.03^{*}$ \\
\hline LV end-systolic diameter (mm) & $30.4 \pm 6.2$ & $32.5 \pm 8.1$ & $0.04^{*}$ \\
\hline LA diameter (mm) & $32.6 \pm 6.5$ & $37.3 \pm 5.8$ & $<0.001^{*}$ \\
\hline LV ejection fraction (\%) & $64.4 \pm 7.9$ & $66.2 \pm 9.1$ & 0.17 \\
\hline $\mathrm{E}(\mathrm{cm} / \mathrm{s})$ & $71.4 \pm 20.0$ & $89.4 \pm 32.0$ & $<0.001^{*}$ \\
\hline $\mathrm{A}(\mathrm{cm} / \mathrm{s})$ & $88.6 \pm 20.2$ & $104.8 \pm 30.1$ & $<0.001^{*}$ \\
\hline$E / A$ & $0.97 \pm 0.46$ & $0.77 \pm 0.35$ & $0.003^{*}$ \\
\hline DT (ms) & $200.9 \pm 45.2$ & $238.7 \pm 78.7$ & $<0.001^{*}$ \\
\hline $\mathrm{e}^{\prime}(\mathrm{cm} / \mathrm{s})$ & $7.6 \pm 2.4$ & $5.7 \pm 2.0$ & $<0.001^{*}$ \\
\hline$E / e^{\prime}$ & $10.2 \pm 4.0$ & $17.0 \pm 8.1$ & $<0.001^{*}$ \\
\hline $\mathrm{LV}$ mass index $\left(\mathrm{g} / \mathrm{cm}^{3}\right)$ & $213.4 \pm 63.9$ & $245.3 \pm 77.6$ & $0.03^{*}$ \\
\hline $\mathrm{EpF}(\mathrm{mm})$ & $2.8 \pm 1.6$ & $5.1 \pm 2.6$ & $<0.001^{*}$ \\
\hline \multicolumn{4}{|l|}{ Adipose tissue distribution } \\
\hline Total fat $\left(\mathrm{cm}^{2}\right)$ & $242.7 \pm 87.2$ & $335.0 \pm 207.5$ & $0.001^{*}$ \\
\hline Subcutaneous fat $\left(\mathrm{cm}^{2}\right)$ & $123.8 \pm 60.6$ & $170.2 \pm 79.3$ & $0.001^{*}$ \\
\hline Visceral fat $\left(\mathrm{cm}^{2}\right)$ & $89.3 \pm 60.4$ & $128.1 \pm 77.1$ & $0.006^{*}$ \\
\hline Peritoneal fat $\left(\mathrm{cm}^{2}\right)$ & $52.2 \pm 45.9$ & $88.5 \pm 71.2$ & $0.003^{*}$ \\
\hline Retroperitoneal fat $\left(\mathrm{cm}^{2}\right)$ & $385.0 \pm 241.5$ & $481.3 \pm 289.1$ & 0.07 \\
\hline
\end{tabular}

The data are presented as the mean \pm standard deviation unless otherwise indicated.

Abbreviations: LVDD left ventricular diastolic dysfunction; BMI body mass index; WC waist circumference; DM diabetes mellitus; CGN chronic glomerular nephritis; HTN hypertension; HOMA homeostasis model of insulin resistance; CRP C-reactive protein; $L D L$ low density lipoprotein; $H D L$ high density lipoprotein; $T G$ triglyceride; $P D$ peritoneal dialysis; $\mathrm{kt} / \mathrm{v}, \mathrm{k}=$ dialyzer clearance of urea, $\mathrm{t}=$ dialysis time, $\mathrm{v}=$ volume of distribution of urea, approximately equal to the patient's total body water; $L A$ left atrial; $L V$ left ventricular; $E$ mitral inflow $E$ wave; $A$ mitral inflow $A$ wave; $D T$ mitral inflow deceleration time; $\mathrm{e}^{\prime}$, peak annular early diastolic velocity of the lateral mitral annulus in tissue Doppler imaging; IVRT interventricular relaxation time; EpF epicardial fat. *, $\mathrm{p}<0.05$. tissue Doppler imaging $(\mathrm{p}<0.001)$ among the patients with LVDD.

Comparison of the anthropometric characteristics showed higher levels of markers reflecting fat distribution, such as the amounts of total, subcutaneous, visceral, and peritoneal fat $(\mathrm{p}<0.001, \mathrm{p}<0.001, \mathrm{p}<0.01$, and $\mathrm{p}<0.005$, respectively), in the LVDD group.

\section{Correlation between EpF thickness and LVDD}

The bivariate Pearson correlation coefficients for LV diastolic function parameters and EpF are shown in Figure 2. EpF was significantly associated with tissue Doppler e, E/e, and DT $(\mathrm{r}=-0.39, \mathrm{p}<0.001 ; \mathrm{r}=0.27, \mathrm{p}=0.001 ; \mathrm{r}=0.29$, $\mathrm{p}<0.001$, respectively) (Figure $2 \mathrm{~A}-\mathrm{C}$ ). EpF thickness was greater in patients with LVDD $(\mathrm{n}=65 ; 5.1 \pm 2.6 \mathrm{~mm})$ than in controls ( $\mathrm{n}=84 ; 2.8 \pm 1.6 \mathrm{~mm}, \mathrm{p}<0.001$, Figure 2D).

\section{Factors associated with LVDD}

We performed univariate analysis to determine the risk factors associated with the development of LVDD. Hypertension, the natural logarithm of the LDL level [Ln(LDL)], $\mathrm{Ln}$ (Visceral fat), $\operatorname{Ln}$ (Peritoneal fat), the hsCRP level, Ln(LV mass index) and EpF thickness were significantly associated with the presence of LVDD (Table 2).

\section{Accumulation of EpF rather than visceral fat is an independent risk factor for LVDD}

We previously found subclinical inflammation (e.g., the plasma hsCRP level) to be an independent risk factor for LVDD in patients with metabolic syndromes [4]. We therefore performed multivariate analysis of the risk factors other than adiposity that were associated with LVDD in our univariate analyses and found that the hsCRP level remained associated with LVDD after adjustment for age, gender, diabetes mellitus, hypertension, the hsCRP and LDL levels, and the LV mass index (OR: 1.75, 95\% CI: 1.08-3.12, $\mathrm{p}=0.038$; Table 3, model 1).

We further evaluated fat distribution and its association with LVDD by multivariate regression analysis. Of the CT measures of fat distribution, $\mathrm{Ln}$ (visceral fat) and Ln(peritoneal fat) remained associated with LVDD after adjustment for the abovementioned confounding factors (adjusted OR $=2.29,95 \% \mathrm{CI}=1.06-5.57, \mathrm{p}=0.013$ and adjusted $\mathrm{OR}=2.45,95 \% \mathrm{CI}=1.1-5.9, \mathrm{p}=0.011$ respectively; Table 3, models $2-3$ ). We repeated the multivariate analysis with adjustment for the hsCRP level and found that this abolished the associations of visceral and peritoneal fat with LVDD. The effect of the hsCRP level itself remained significant in both models $(\mathrm{OR}=2.56,95 \% \mathrm{CI}=$ $1.08-4.72, \mathrm{p}=0.023$ and $\mathrm{OR}=2.70,95 \% \mathrm{CI}=1.21-6.69$, $\mathrm{p}=0.019$, respectively; Table 3 , model 4 and model 5), indicating that hsCRP might mediate the effect of visceral and/or peritoneal fat on LVDD. To elucidate the influence of EpF, we adjusted for all of the confounding factors and 

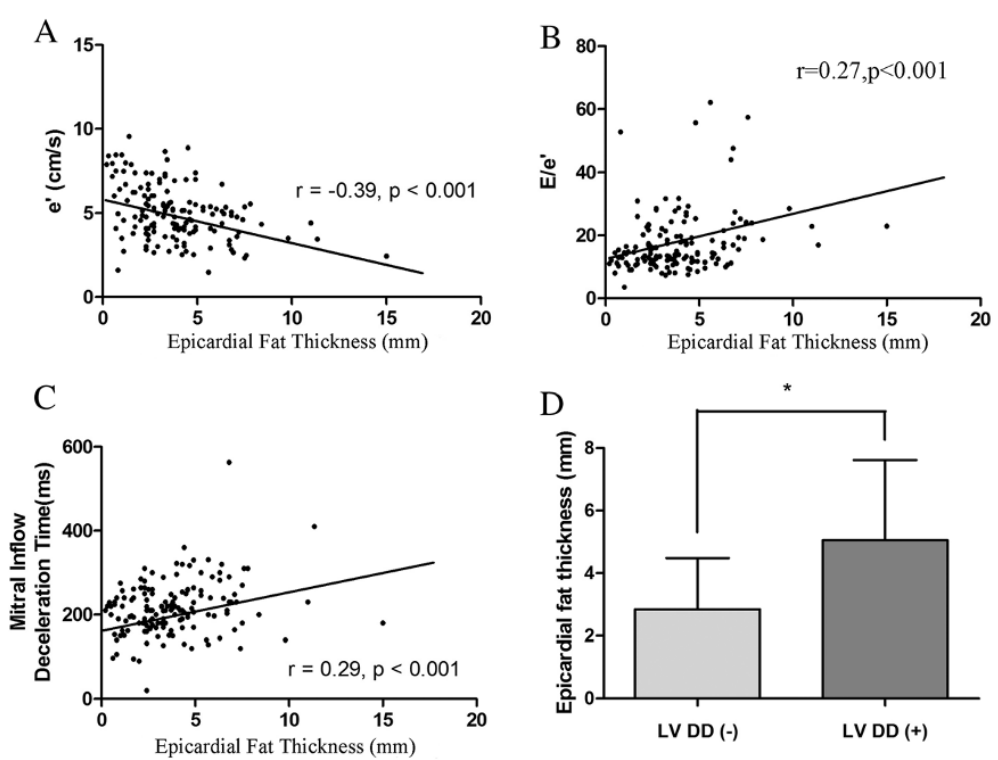

Figure 2 Correlation between epicardial fat (EpF) thickness and left ventricular diastolic dysfunction (LVDD). EpF thickness correlated significantly with (A) $e^{\prime}(r=-0.39, p<0.001)$, (B) E/e' $(r=0.27, p<0.001)$, and (C) mitral inflow deceleration time $(r=0.29, p=0.002)$. (D) EpF thickness in patients with or without left ventricular diastolic dysfunction (LVDD). The bar graph shows the mean + standard deviation. EpF thickness was significantly greater in patients with LVDD $\left(5.1 \pm 2.6 \mathrm{~cm}^{3}\right)$ than in controls $\left(2.8 \pm 1.6 \mathrm{~cm}^{3}, p<0.001\right)$.

parameters of inflammation and adiposity simultaneously in model 6. EpF remained an independent, significant predictor of the presence of LVDD in this model, which may imply that EpF influences LV diastolic function through pathways other than subclinical inflammation.

Table 2 Univariate logistic regression analyses of risk factors associated with the presence of LVDD

\begin{tabular}{lcc}
\hline & OR (95\% Cl) & $\mathbf{p}$ \\
\hline Age & $1.02(0.99-1.04)$ & 0.14 \\
Gender & $1.53(0.80-2.94)$ & 0.21 \\
BMI & $1.05(0.92-1.20)$ & 0.45 \\
DM & $1.66(0.83-3.31)$ & 0.15 \\
Hypertension & $4.11(1.80-9.42)$ & $<0.001$ \\
Ln(LDL) & $3.38(1.01-11.36)$ & 0.049 \\
Ln(TG) & $0.95(0.48-1.88)$ & 0.88 \\
Ln(Visceral fat) & $2.09(1.18-3.68)$ & 0.01 \\
Ln(Peritoneal fat) & $1.92(1.22-3.02)$ & 0.005 \\
hsCRP & $2.09(1.56-2.79)$ & $<0.001$ \\
Ln(LV mass index) & $4.98(1.10-22.64)$ & 0.03 \\
EpF & $1.75(1.41-2.17)$ & $<0.001$
\end{tabular}

Abbreviations: $L V D D$, left ventricular diastolic dysfunction; $O R$, odds ratio; $C l$, confidence interval; $B M I$, body mass index; $D M$, diabetes mellitus; $L n(L D L)$, natural logarithm of low-density lipoprotein; $T G$, triglyceride; $h s C R P$, high-sensitivity $C$-reactive protein; $L V$, left ventricular; $E p F$, epicardial fat. ORs and $95 \% \mathrm{Cls}$ were estimated by logistic regression.

\section{Discussion}

In this study, we found that EpF thickness in patients undergoing PD patients correlates with LVDD even after adjustment for all of the confounding factors, whereas visceral fat was not significantly independently associated with LVDD. In addition, LVDD was significantly associated with the hsCRP level in this specific group of patients. Inflammation and EpF were the 2 most important risk factors for LVDD, implying that these factors might act synergistically.

Although there is no published figure for the prevalence of diastolic heart failure in patients undergoing PD, LV diastolic heart failure would be expected more frequently among patients with ESRD than in the general population due to the inflammation, fluid overload, hypertension, renin-angiotensin-aldosterone system activation, and LV hypertrophy associated with ESRD [2,23]. Abnormal fat distribution seems a likely culprit for the high prevalence of LVDD in patients undergoing PD. Such patients tend to have elevated amounts of intraabdominal fat [24], and we recently found higher amounts of visceral adipose tissue to be associated with low-grade inflammation, which leads in turn to subclinical LVDD [4]. However, the current study is to the best of our knowledge the first report that inflammation and EpF content are independent risk factors for LVDD in patients with PD and thus suggests some explanations for the prevalence of LVDD in this group. EpF is 
Table 3 Multivariate logistic regression models for parameters associated with left ventricular diastolic dysfunction

\begin{tabular}{|c|c|c|c|}
\hline & Odds ratio & $95 \%$ Confidence interval & $p$ \\
\hline \multicolumn{4}{|l|}{ Model 1} \\
\hline Age & 1.07 & $1.01-1.14$ & $0.018^{*}$ \\
\hline Ln(LV mass index $)$ & 14.88 & $1.91-115.7$ & $0.01^{*}$ \\
\hline DM & 1.60 & 0 50-5.12 & 0.425 \\
\hline HTN & 2.18 & $0.48-9.93$ & 0.313 \\
\hline $\operatorname{Ln}(\mathrm{LDL})$ & 5.54 & $1.31-23.52$ & $0.02^{*}$ \\
\hline hsCRP & 1.75 & $1.08-3.12$ & $0.038^{*}$ \\
\hline \multicolumn{4}{|l|}{ Model 2} \\
\hline Ln(Visceral Fat) & 2.29 & $1.06-5.57$ & $0.013^{*}$ \\
\hline \multicolumn{4}{|l|}{ Model 3} \\
\hline Ln(Peritoneal Fat) & 2.45 & $1.1-5.92$ & $0.011^{*}$ \\
\hline \multicolumn{4}{|l|}{ Model 4} \\
\hline Ln(Visceral Fat) & 2.10 & $0.85-6.43$ & 0.344 \\
\hline hsCRP & 2.56 & $1.08-4.72$ & $0.023^{*}$ \\
\hline \multicolumn{4}{|l|}{ Model 5} \\
\hline Ln(Peritoneal Fat) & 2.23 & $0.85-6.78$ & 0.268 \\
\hline hsCRP & 2.23 & $1.21-6.69$ & $0.019^{*}$ \\
\hline \multicolumn{4}{|l|}{ Model 6} \\
\hline EpF & 2.41 & $1.43-4.08$ & $0.01^{*}$ \\
\hline Ln(visceral Fat) & 2.04 & $0.48-6.68$ & 0.14 \\
\hline Peritoneal Fat & 3.15 & $0.12-8.65$ & 0.50 \\
\hline hsCRP & 3.03 & $1.26-7.30$ & $0.01^{*}$ \\
\hline
\end{tabular}

Abbreviations: $\operatorname{Ln}(L V$ mass index), natural logarithm of the left ventricular mass index; $D M$, diabetes mellitus; HTN, hypertension; $h S C R P$, high-sensitivity $C$-reactive protein; $L D L$, low-density lipoprotein; $E p F$, epicardial fat. Odds ratios and $95 \%$ confidence intervals were estimated by logistic regression. Models 2-6 adjust for age, DM, HTN, Ln(LDL), and $\operatorname{Ln}(\mathrm{LV}$ mass index). Model 4 and model 5 additionally adjust for hsCRP. Model 6 additionally adjusts for hsCRP and adiposity components. ${ }^{*}, \mathrm{p}<0.05$.

characterized by a high rate of release of free fatty acids (FFA) [25], which encounter no physical barrier or fascia before reaching the cardiomyocytes [26]; therefore, the myocardium receives a double dose of FFA from both the EpF and the systemic circulation.

There are also hypothesis that EpF can influence LV diastolic function. EpF is a source of several bioactive molecules that might directly influence the myocardium [27]. In metabolic and cardiovascular disease states, these fat tissues expand, becoming hypoxic and dysfunctional $[28,29]$ and recruiting phagocytic cells [30] which would lead to reducing the production of protective cytokines, increasing detrimental adipocytokines and impaired cardiac function eventually. Besides, Iozzo P et al. have documented that the entire mass of fat surrounding the heart ranges on average from $100 \mathrm{~g}$ (healthy individual) to $400 \mathrm{~g}$ (type II DM patient), extending to $800 \sim 900 \mathrm{~g}$ in some patients [31]. This weight probably poses a mechanical burden on cardiac expansion, and may further deteriorate LVDD in PD patients. The diagram for the above discussion is summarized in Additional file 1.

Increased levels of myocardial triglycerides could cause cardiomyocyte apoptosis, increased oxidative stress, and impairment of cardiac function. Kankaanpää et al. evaluated EpF and left ventricular (LV) function using MRI and concluded that FFA exposure and EpF may increase accumulation of myocardial triglycerides, which might have negative effect for LV overload and hypertrophy [32]. A recent study assessing the association between echocardiographic EpF and myocardial fat found that echocardiographic EpF accumulation might reflect myocardial fat in subjects with a wide range of adiposity [22]. Taken together, the current study and previous evidence suggest that the mechanisms delineated in animal models also operate in patients undergoing PD. These patients have abnormal fat distribution, and accumulation of fat, especially visceral fat, can potently exacerbate inflammation. In addition, recent studies show that epicardial adipose tissue plays an important role of development and progression of CAD. Elevated inflammatory infiltrate has been described in $\mathrm{EpF}$ of subjects with CAD [33]. When compared with subcutaneous fat, inflammatory cell infiltration, mainly contributed by macrophages, is enhanced in epicardial adipose tissue $[33,34]$. Besides of macrophage accumulation, macrophage phenotypic change in epicardial adipose tissue of CAD patients is also demonstrated [35]. Moreover, as we look into the role of visceral fat in the pathogenesis of CAD, there is evidence which suggests that not only EpF but mediastinal adipose tissue contributes locally to the development of coronary atherosclerosis via glucocorticoid action [36]. Increased epicardial fat thickness is shown to be an independent risk factor for CAD in specific patients [37], and there are probably gender disparities in the association between epicardial adipose tissue volume and CAD [38].

In our current study, we measured the amount of EpF by echocardiography. Malavazos et al. [22] documented that echocardiographic measurement accurately estimates the actual amount of EpF, which could be a strong and independent predictor of myocardial fat (represented by triglycerides stored within the cardiac muscle tissue). Echocardiographic EpF measurement has advantages for use in both clinical and research settings, including low cost, routine applicability, avoidance of exposure to radiation, and potential for monitoring therapeutic effects. As myocardial fat has progressive and harmful effects on LV diastolic function, accumulation of EpF may affect the heart as well [39]. Atrial enlargement has been shown to correlate with impairment 
in diastolic filling in morbidly obese subjects [40]. In our current study, we controlled for the influence of systemic adiposity and its effect via systemic inflammation and still found an independent role for the amount of EpF in the development of LVDD. These results not only reveal that EpF directly reflects myocardial fat content but also allow us to monitor early myocardial changes in patients undergoing PD. This convenient method might even be able to detect the development of LVDD, allowing early initiation of treatment and monitoring of the response of therapy, which is especially important in patients with multiple co-morbidities.

An elevated or excessive amount of adipose tissue is regarded as a risk factor for a number of diseases, including insulin resistance, type 2 diabetes mellitus, and atherosclerosis, all of which can lead to major cardiovascular sequelae. Further, adipose tissue is associated with changes in both inflammatory cells and biochemical markers of inflammation [23,41]. In the current study, we demonstrated that inflammation and accumulation of EpF play pivotal roles in the development of LVDD in patients undergoing PD. However, the associations therewith of visceral and peritoneal adipose tissue were no longer significant after adjustment for inflammation. We recently assessed the role of pro-inflammatory cytokines in the relationship between inflammation and LVDD in patients undergoing PD [42]. That study identified a significant correlation between LVDD and serum markers of inflammation in patients undergoing PD and an interaction between PD and inflammation. Taking these results together with the findings of the current study, we speculate that the systemic load of adipose tissue in patients undergoing PD might increase the susceptibility to LVDD through inflammation, while EpF represents the true amount of myocardial fat and thus acts independently. Inflammation (contributed in part by systemic adipose tissue) and increase of triglycerides stored within the cardiac muscle tissue (proportional to $\mathrm{EpF}$ ) could therefore act synergistically to cause LVDD.

Our study had several limitations. First, we used crosssectional data to infer longitudinal relationships. Although a model was identified, additional associations and possible pathways may exist, and further, prospective studies will be necessary to delineate a precise causal relationship. Second, all of the patients in our current study are Taiwanese. The generalizability to other population should be demonstrated by further study. Third, the effects of LVDD and EpF thickness on the long-term outcomes of patients undergoing PD warrant further investigation.

In conclusion, we delineated for the first time the complex relationships among EpF accumulation, inflammation, and LVDD in patients undergoing PD. This study demonstrated that the amount of EpF but not visceral adipose tissue is independently associated with subclinical LVDD in patients undergoing PD.

\section{Additional file}

Additional file 1: The diagram for the hypothesis of how epicardial fat influence left ventircular diastolic function.

\section{Abbreviations}

CVD: Cardiovascular disease; ESRD: End-stage renal disease; PD: Peritoneal dialysis; LVDD: Left ventricular diastolic dysfunction; EpF: Epicardial fat; CAD: Coronary artery disease; HSCRP: High sensitivity c-reactive protein; BMI: Body mass index; DM: Diabetes mellitus; HOMA: Homeostasis model of insulin resistance; LDL: Low density lipoprotein; HDL: High density lipoprotein; TG: Triglyceride; E: Mitral inflow E wave; A: Mitral inflow A wave; DT: Mitral inflow deceleration time; e': Peak annular early diastolic velocity of the lateral mitral annulus in tissue doppler imaging.

\section{Competing interests}

The corresponding author has full access to all of the data in the study and takes responsibility for the integrity of the data and the accuracy of the data analysis. The authors declare that they have no competing interests.

\section{Authors' contributions}

Regarding the contribution of each author, CW designed the whole study. $C Y$ and $J \mathrm{~L}$ analyzed and interpreted the data. $Y L, H L, C W$ performed the laboratory work, and wrote the manuscript. CW, JH recruited the patients, and critically reviewed the manuscript for important intellectual content. CW was also in charge of the whole program. All authors read and approved the final manuscript.

\section{Acknowledgement}

This work was supported in part by the research grants from the Far Eastern Memorial Hospital (FEMH-2013-D-030), grants from the IBMS CRC Research Program of the Institute of Biomedical Sciences, Academia Sinica (IBMSCRC102-P01), the National Science Council of the Republic of China (NSC 992314-B-002-131-MY3, 102-2314-B-002-058-), and the New Century Health Care Promotion Foundation.

\section{Author details}

${ }^{1}$ Division of Cardiology, Department of Internal Medicine, Far Eastern Memorial Hospital, New Taipei City, Taiwan. ${ }^{2}$ Department of Laboratory Medicine, National Taiwan University Hospital, Taipei, Taiwan. ${ }^{3}$ Department of Clinical Pathology \& Cardiovascular Center, Far Eastern Memorial Hospital, New Taipei City, Taiwan. ${ }^{4}$ Graduate Institute of Biomedical Electronics and Bioinformatics, National Taiwan University, Taipei, Taiwan. ${ }^{5}$ Department of Medical Imaging, National Taiwan University College of Medicine and Hospital, Taipei, Taiwan. ${ }^{6}$ Division of Nephrology, Department of Internal Medicine, National Taiwan University College of Medicine and Hospital, Taipei, Taiwan. ${ }^{7}$ Division of Cardiology, Department of Internal Medicine, National Taiwan University College of Medicine and Hospital No. 7,

Chung-Shan South Road Taipei 100, Taipei, Taiwan. ${ }^{8}$ Graduate Institute of Clinical Medicine, College of Medicine, National Taiwan University, Taipei, Taiwan.

Received: 26 June 2013 Accepted: 10 August 2013 Published: 30 August 2013

\section{References}

1. Foley RN, Parfrey PS, Sarnak MJ: Clinical epidemiology of cardiovascular disease in chronic renal disease. Am J Kidney Dis 1998, 32:S112-S119.

2. Bajraktari G, Berbatovci-Ukimeraj M, Hajdari A, Ibraimi L, Daullxhiu I, Elezi $Y$, Ndrepepa G: Predictors of increased left ventricular filling pressure in dialysis patients with preserved left ventricular ejection fraction.

Croat Med J 2009, 50:543-549.

3. Stenvinkel P: Inflammation in end-stage renal disease: the hidden enemy. Nephrology (Carlton) 2006, 11:36-41.

4. Wu CK, Yang CY, Lin JW, Hsieh HJ, Chiu FC, Chen JJ, Lee JK, Huang SW, Li HY, Chiang FT, Tsai CT: The relationship among central obesity, systemic inflammation, and left ventricular diastolic dysfunction as determined by structural equation modeling. Obesity (Silver Spring) 2012, 20:730-737. 
5. London GM: Cardiovascular disease in chronic renal failure: pathophysiologic aspects. Semin Dial 2003, 16:85-94.

6. Ikonomidis I, Nikolaou M, Dimopoulou I, Paraskevaidis I, Lekakis J, Mavrou I, Tzanela M, Kopterides P, Tsangaris I, Armaganidis A, Kremastinos DT: Association of left ventricular diastolic dysfunction with elevated ntpro-bnp in general intensive care unit patients with preserved ejection fraction: a complementary role of tissue doppler imaging parameters and nt-pro-bnp levels for adverse outcome. Shock 2010, 33:141-148.

7. Fontan MP, Rodriguez-Carmona A, Cordido F, Garcia-Buela J: Hyperleptinemia in uremic patients undergoing conservative management, peritoneal dialysis, and hemodialysis: a comparative analysis. Am J Kidney Dis 1999, 34:824-831.

8. Huang JW, Yen CJ, Chiang HW, Hung KY, Tsai TJ, Wu KD: Adiponectin in peritoneal dialysis patients: a comparison with hemodialysis patients and subjects with normal renal function. Am J Kidney Dis 2004, 43:1047-1055

9. Jager KJ, Merkus MP, Huisman RM, Boeschoten EW, Dekker FW, Korevaar JC, Tijssen JG, Krediet RT: Nutritional status over time in hemodialysis and peritoneal dialysis. JASN 2001, 12:1272-1279.

10. Choi SJ, Kim NR, Hong SA, Lee WB, Park MY, Kim JK, Hwang SD, Lee HK: Changes in body fat mass in patients after starting peritoneal dialysis. Perit Dial Int 2011, 31:67-73.

11. Deswal A, Petersen NJ, Feldman AM, Young JB, White BG, Mann DL: Cytokines and cytokine receptors in advanced heart failure: an analysis of the cytokine database from the vesnarinone trial (vest). Circulation 2001, 103:2055-2059.

12. lacobellis $\mathrm{G}$ and Willens $\mathrm{HJ}$ : Echocardiographic epicardial fat: a review of research and clinical applications. J Am Soc Echocardiogr 2009, 22:1311-1319. quiz 1417-1318.

13. Mazurek T, Zhang L, Zalewski A, Mannion JD, Diehl JT, Arafat H, Sarov-Blat L, O'Brien S, Keiper EA, Johnson AG, Martin J, Goldstein BJ, Shi Y: Human epicardial adipose tissue is a source of inflammatory mediators. Circulation 2003, 108:2460-2466.

14. Kremen J, Dolinkova M, Krajickova J, Blaha J, Anderlova K, Lacinova Z, Haluzikova D, Bosanska L, Vokurka M, Svacina S, Haluzik M: Increased subcutaneous and epicardial adipose tissue production of proinflammatory cytokines in cardiac surgery patients: possible role in postoperative insulin resistance. J Clin Endocrinol Metab 2006, 91:4620-4627.

15. Nakazato R, Dey D, Cheng VY, Gransar H, Slomka PJ, Hayes SW, Thomson LE, Friedman JD, Min JK, Berman DS: Epicardial fat volume and concurrent presence of both myocardial ischemia and obstructive coronary artery disease. Atherosclerosis 2012, 221:422-426.

16. Cavalcante JL, Tamarappoo BK, Hachamovitch R, Kwon DH, Alraies MC, Halliburton S, Schoenhagen P, Dey D, Berman DS, Marwick TH: Association of epicardial fat, hypertension, subclinical coronary artery disease, and metabolic syndrome with left ventricular diastolic dysfunction. Am J Cardiol 2012, 110:1793-1798.

17. Khawaja T, Greer C, Chokshi A, Chavarria N, Thadani S, Jones M, Schaefle K, Bhatia K, Collado JE, Shimbo D, Einstein AJ, Schulze PC: Epicardial fat volume in patients with left ventricular systolic dysfunction. Am J Cardiol 2011, 108:397-401.

18. Wu CK, Luo JL, Tsai CT, Huang YT, Cheng CL, Lee JK, Lin LY, Lin JW, Hwang JJ, Chiang FT: Demonstrating the pharmacogenetic effects of angiotensin-converting enzyme inhibitors on long-term prognosis of diastolic heart failure. Pharmacogenomics J 2010 Feb, 10(1):46-53.

19. Wu CK, Lee JK, Chiang FT, Yang CH, Huang SW, Hwang JJ, Lin JL, Tseng CD, Chen JJ, Tsai CT: Plasma levels of tumor necrosis factor-alpha and interleukin- 6 are associated with diastolic heart failure through downregulation of sarcoplasmic reticulum ca2+ atpase. Crit Care Med 2011, 39:984-992.

20. Wu CK, Tsai CT, Chang YC, Luo JL, Wang YC, Hwang JJ, Lin JL, Tseng CD, Chiang FT: Genetic polymorphisms of the angiotensin ii type 1 receptor gene and diastolic heart failure. J Hypertens 2009, 27:502-507

21. Devereux RB, Alonso DR, Lutas EM, Gottlieb GJ, Campo E, Sachs I, Reichek N: Echocardiographic assessment of left ventricular hypertrophy: comparison to necropsy findings. Am J Cardiol 1986, 57:450-458

22. Malavazos AE, Di Leo G, Secchi F, Lupo EN, Dogliotti G, Coman C, Morricone L, Corsi MM, Sardanelli F, lacobellis G: Relation of echocardiographic epicardial fat thickness and myocardial fat. Am J Cardio/ 2010, 105:1831-1835.
23. Hirota H, Yoshida K, Kishimoto T, Taga T: Continuous activation of gp130, a signal-transducing receptor component for interleukin 6-related cytokines, causes myocardial hypertrophy in mice. Proc Natl Acad Sci U S A 1995, 92:4862-4866.

24. Fernstrom A, Hylander B, Moritz A, Jacobsson H, Rossner S: Increase of intra-abdominal fat in patients treated with continuous ambulatory peritoneal dialysis. Perit Dial Int 1998, 18:166-171.

25. Marchington JM, Mattacks CA, Pond CM: Adipose tissue in the mammalian heart and pericardium: structure, foetal development and biochemical properties. Comp Biochem Physiol B 1989, 94:225-232.

26. lacobellis G, Corradi D, Sharma AM: Epicardial adipose tissue: anatomic, biomolecular and clinical relationships with the heart. Nat Clin Pract Cardiovasc Med 2005, 2:536-543.

27. Iozzo P: Myocardial, perivascular, and epicardial fat. Diabetes Care 2011, 34(Suppl 2):S371-S379.

28. Greenstein AS, Khavandi K, Withers SB, Sonoyama K, Clancy O, Jeziorska M, Laing I, Yates AP, Pemberton PW, Malik RA, Heagerty AM: Local inflammation and hypoxia abolish the protective anticontractile properties of perivascular fat in obese patients. Circulation 2009, 119:1661-1670.

29. Pang C, Gao Z, Yin J, Zhang J, Jia W, Ye J: Macrophage infiltration into adipose tissue may promote angiogenesis for adipose tissue remodeling in obesity. Am J Physiol Endocrinol Metab 2008, 295:E313-E322.

30. Henrichot E, Juge-Aubry CE, Pernin A, Pache JC, Velebit V, Dayer JM, Meda P, Chizzolini C, Meier CA: Production of chemokines by perivascular adipose tissue: a role in the pathogenesis of atherosclerosis? Arterioscler Thromb Vasc Biol 2005, 25:2594-2599.

31. Iozzo P, Lautamaki R, Borra R, Lehto HR, Bucci M, Viljanen A, Parkka J, Lepomaki V, Maggio R, Parkkola R, Knuuti J, Nuutila P: Contribution of glucose tolerance and gender to cardiac adiposity. J Clin Endocrinol Metab 2009, 94:4472-4482.

32. Kankaanpaa M, Lehto HR, Parkka JP, Komu M, Viljanen A, Ferrannini $E_{\text {, }}$ Knuuti J, Nuutila P, Parkkola R, lozzo P: Myocardial triglyceride content and epicardial fat mass in human obesity: relationship to left ventricular function and serum free fatty acid levels. J Clin Endocrinol Metab 2006, 91:4689-4695

33. Baker AR, Harte AL, Howell N, Pritlove DC, Ranasinghe AM, Da Silva NF, Youssef EM, Khunti K, Davies MJ, Bonser RS, Kumar S, Pagano D, McTernan PG: Epicardial adipose tissue as a source of nuclear factorkappaB and c-Jun N-terminal kinase mediated inflammation in patients with coronary artery disease. J Clin Endocrinol Metab 2009, 94:261-267.

34. Hirata $Y$, Kurobe $H$, Akaike M, Chikugo F, Hori T, Bando Y, Nishio C, Higashida M, Nakaya Y, Kitagawa T, Sata M: Enhanced inflammation in epicardial fat in patients with coronary artery disease. Int Heart J 2011, 52:139-142.

35. Hirata Y, Tabata M, Kurobe H, Motoki T, Akaike M, Nishio C, Higashida M, Mikasa H, Nakaya Y, Takanashi S, Igarashi T, Kitagawa T, Sata M: Coronary atherosclerosis is associated with macrophage polarization in epicardial adipose tissue. J Am Coll Cardiol 2011, 58:248-255.

36. Atalar F, Gormez S, Caynak B, Akan G, Tanriverdi G, Bilgic-Gazioglu S, Gunay D, Duran C, Akpinar B, Ozbek U, Buyukdevrim AS, Yazici Z: The role of mediastinal adipose tissue 11 beta-hydroxysteroid d ehydrogenase type 1 and glucocorticoid expression in the development of coronary atherosclerosis in obese patients with ischemic heart disease. Cardiovasc Diabetol 2012, 11:115.

37. Kim HM, Kim KJ, Lee HJ, Yu HT, Moon JH, Kang ES, Cha BS, Lee HC, Lee BW, Kim YJ: Epicardial adipose tissue thickness is an indicator for coronary artery stenosis in asymptomatic type 2 diabetic patients: its assessment by cardiac magnetic resonance. Cardiovasc Diabetol 2012, 11:83

38. Dagvasumberel M, Shimabukuro M, Nishiuchi T, Ueno J, Takao S, Fukuda D, Hirata Y, Kurobe H, Soeki T, Iwase T, Kusunose K, Niki T, Yamaguchi K, Taketani Y, Yagi S, Tomita N, Yamada H, Wakatsuki T, Harada M, Kitagawa T, Sata M: Gender disparities in the association between epicardial adipose tissue volume and coronary atherosclerosis: A 3-dimensional cardiac computed tomography imaging study in japanese subjects. Cardiovasc Diabetol 2012, 11:106.

39. van der Meer RW, Rijzewijk LJ, Diamant M, Hammer S, Schar M, Bax JJ, Smit JW, Romijn JA, de Roos A, Lamb HJ: The ageing male heart: myocardial triglyceride content as independent predictor of diastolic function. Eur Heart J 2008, 29:1516-1522. 
40. lacobellis G, Leonetti F, Singh N, Sharma AM: Relationship of epicardial adipose tissue with atrial dimensions and diastolic function in morbidly obese subjects. Int J Cardiol 2007, 115:272-273.

41. Finkel MS, Oddis CV, Jacob TD, Watkins SC, Hattler BG, Simmons RL: Negative inotropic effects of cytokines on the heart mediated by nitric oxide. Science 1992, 257:387-389.

42. Lee JK, Lin HH, Tsai CT, Chen JJ, Kuo CC, Lien YC, Lin JW, Huang JW, Hwang SW, Hwang JJ, Tseng CD, Chiang FT, Wu CK: Differential association of proinflammatory cytokines with left ventricular diastolic dysfunction in subjects with and without continuous ambulatory peritoneal dialysis. Nutr Metab Cardiovasc Dis 2012, 22:974-980.

doi:10.1186/1475-2840-12-127

Cite this article as: Lin et al: Accumulation of epicardial fat rather than visceral fat is an independent risk factor for left ventricular diastolic dysfunction in patients undergoing peritoneal dialysis. Cardiovascular Diabetology 2013 12:127.

\section{Submit your next manuscript to BioMed Central and take full advantage of:}

- Convenient online submission

- Thorough peer review

- No space constraints or color figure charges

- Immediate publication on acceptance

- Inclusion in PubMed, CAS, Scopus and Google Scholar

- Research which is freely available for redistribution 